\title{
Beyond the outcomes: generic change indicators in a video-feedback intervention with a depressed mother and her baby: a single case study
}

\author{
Catalina Sieverson, ${ }^{1}$ Marcia Olhaberry, ${ }^{2}$ Javiera Duarte, ${ }^{3}$ Javier Morán-Kneer, ${ }^{4}$ Stefanella Costa, ${ }^{3}$ M. José León, ${ }^{1}$ \\ Sofía Valenzuela, ${ }^{1}$ Fanny Leyton, ${ }^{5}$ Carolina Honorato, ${ }^{1}$ Antonia Muzard ${ }^{2}$
}

${ }^{1}$ Milenium Institute for depression and Personality Research (MIDAP), Macul, Santiago; ${ }^{2}$ Psychology Faculty, Pontificia Universidad Católica, Macul, Santiago; ${ }^{3}$ Psychology Faculty, Universidad Diego Portales, Santiago Centro, Santiago; ${ }^{4}$ Psychology Faculty, Universidad de Valparaíso, Valparaíso; ${ }^{5}$ Child Inpatient Unit, Psychiatric Hospital del Salvador, Valparaíso, Chile

\begin{abstract}
\end{abstract}
Child and dyadic psychotherapy have been scarcely investigated from the psychotherapy process research perspective. Thus, content and mechanisms related to therapeutic change have been overlooked by research. This study aimed at testing the applicability of the generic change indicators (GCI) model to identify moments of change in the parent during dyadic interventions, as well as to explore, describe and illustrate the therapeutic process through a brief mentalization-informed intervention with a depressive mother and her baby, using video-feedback as its main strategy, which has ample evidence about its effectiveness. We conducted a single case qualitative study using the GCI model. The mother's ongoing change was determined by identifying episodes of change (EC) and moments of change (MC). Each MC was then labelled with one of the 19 GCIs. GCIs were observed from the intervention's start. GCI's hierarchical levels were increasing over the intervention, in association with the video-feedback situation. Our findings suggest that the GCI model is feasible to observe and understand dyadic interventions, contributing to the growing body of evidence supporting psychotherapists' training and supervision.

Key words: Psychotherapy research; video-feedback; early childhood intervention; mother-child intervention; peripartum depression.

\section{Introduction}

Depression is the most common mental health disorder in mothers during the peripartum period (Hahn-Holbrook et al., 2018). When peripartum depressive symptoms are untreated (Diagnostic and Statistical Manual of Mental Disorders, 5th Edition), this may lead to the development of several relational difficulties between the mother and her baby (Beebe, 2003; Feldman, 2015; McFarquhar et al., 2018; Monk et al., 2012; Racine et al., 2018). Peripartum depression has been associated with higher levels of maternal stress and anxiety (Morgan et al., 2021; Stein et al., 2014), which in turn negatively impact dyadic adjustment (Vismara et al., 2016; Rolle et al., 2017), as well as lower maternal responsiveness to her baby's cues and needs (Behrendt, Scharke, Herpertz-Dahlmann, Konrad, \& Firk, 2019; Lefkovics, et al., 2018). Thus, peripartum depression is a risk factor for infant development, attachment, and mother-baby interaction quality, even at subclinical levels (Tronick \& Reck, 2009). 
Even though in an extensive literature review, Cox et al. (2016) reported that although peripartum depression is prevalent, about $50 \%$ of cases go undiagnosed. Likewise, almost $90 \%$ of women with peripartum depressive symptomatology do not receive adequate treatment.

Notwithstanding, there is a body of evidence that suggests that interventions for peripartum depression during postnatal period are effective in reducing symptoms, improving mothers' social adjustment and improving the quality of the mother-baby bond (Letourneau et al., 2017; Newton et al., 2020; Olhaberry et al., 2013). In a review, Newton et al. (2020) reported that those mothers with depressive symptomatology who received treatment showed significant improvements in both mother-infant relationship as well as in their infant's development.

Although there is a diversity of interventions, there are common components across dyadic interventions related to their effectiveness: i) facilitating positive mother-infant interactions; ii) helping mothers understand their infant's perspective and inner world; and iii) the use of video-feedback.

Even though some studies address these standard components across interventions in infancy, they only focus on outcomes and effectivity (O'Hara et al., 2019; Newton et al., 2020). Very few studies have focused on the psychotherapy process in child therapy (Capella, et al., 2018; Midgley, 2009) and regarding dyadic and video-feedback interventions is even scarcer. There are, however, some examples of research groups that have investigated the processes of therapeutic change in interventions with mother-baby dyads using video-feedback.

Beatrice Beebe (e.g., 2003, 2010) has developed an important line of research exploring intervention and change processes in the mother-infant dyad. In her model, Beebe $(2003,2010)$ identifies three levels of analysis within the mother-infant intervention process that relate to therapeutic change: procedural (how mother and infant influence each other); declarative (which aspects of these influences can the mother verbalize); and representational (how the mother's representations of her baby interfere with her ability to perceive her own nonverbal behaviour).

In Beebe's model, the therapist helps the mother translate what is happening at the procedural level to subsequently describe the video and explore what she was feeling or thinking at that moment. Beebe notices that a critical ingredient of the intervention to promote change is the level of detail in the observation of behaviors, which serves as a springboard for reflective processes (i.e., associations, memories, perceptions) regarding the meaning of those behaviours.

Moreover, Doria et al. (2013) have developed an empirically driven model that explains two mechanisms (M1 and M2) that would underlie the therapeutic change promoted by video-feedback. First, M1 refers to the meta-cog- nitive processes that are activated by viewing him/herself in a different way from his/her negative preconceptions about him/herself. Second, M2 refers to the shared construction of a new reality with the support and collaboration of the facilitator.

Other research groups (e.g. Kennedy et al., 2011; Murphy et al., 2012; Steele et al., 2014) have described the role of the therapist in these interventions as a secure base and safe haven for the patient. This would foster reflective functioning in the mother, promoting exploration in times of calm and containment in times of stress alongside the mother's interaction with her baby (Beebe, 2003). In addition, they are exposed to a video record that is real, that pertains to information-rich past experiences and that has multiple levels of interaction. In this way, the process of observing together with the therapist would provide a more comprehensive and reflective perspective (Steele $e t$ al., 2014).

Several reasons have been described regarding videofeedback's effectiveness and it has become a widely used intervention method in attachment-based interventions (Juffer \& Steele, 2014).

First, moment-to-moment video observation allows for accurate observations of subtle behaviors of both infants and caregivers. Second, this intervention strategy enables to add 'subtitles' to the behaviors, emotions and expressions manifested by the child in the video, 'speaking for the child' and giving meaning to her behaviors (Carter, Osofsky, \& Hann, 1991; Juffer, Bakermans-Kranenburg, \& van IJzendoor, 2018). Third, the therapist can stop and reinforce those positive moments of interaction between adults and their children. Thus, regarding the sensitivity concept of Ainsworth (1978), adults are encouraged to recognize child's perspective and thus be able to improve their observation skills and respond them in a timely and appropriate manner.

Based on Tronick's (2007) research, the intersubjective processes between a mother and her baby are the earliest developmental example of dyadic communication and mutual co-regulation, and this early-rooted mutual influence remains a feature that is actualized in the patient-therapist relationship (Wallin, 2012). During the video-feedback intervention, the main focuses are to observe interactional patterns between the mother and her baby, and intersubjective processes that are activated.

In this sense, studies analyzing psychotherapeutic and intersubjective processes within psychotherapy describe, for example, that patients can recall significant moments of therapy and experience them as emotionally charged and related to the implicit relational domain (Duarte et al., 2020). Another related evidence suggests that desirable interpersonal characteristics and qualities in therapists that influence change processes. Among the characteristics they describe emotional expression, hopefulness, warmth, empathy, and alliance-bond capacity (Anderson, McClintock, Himawan, Song, \& Patterson, 2016) among the in- 
terpersonal qualities are reflective style and internal processes (Reading, Safran, Origlieri, \& Muran, 2019).

Specifically, a reflective mindset in the therapist has been proposed and described as a mechanism that relates to the therapeutic alliance (Taubner, et al., 2011) and facilitates therapeutic change (Antonsen et al., 2016; Gullestad et al., 2013). From mentalization-informed intervention models, studies analysing reflective function in both therapists and patients have shown its influence on both the alliance and outcomes (Ekeblad, Falkenstörm \& Holmqvist, 2016; Antonsen, 2016). Particularly, some authors point out that facilitating patient mentalization during psychotherapy could be a mechanism of psychotherapeutic change in itself (Fisher-Kern et al., 2015).

Research on therapeutic processes has progressed and increased in recent decades, primarily because of the need for research and evidence that accounts for those elements, mechanisms and processes associated with therapeutic change (Krause \& Altimir, 2018). Particularly, a generic model of psychotherapy and therapeutic change (Orlinsky, 1987) could be very useful in trying to understand what and how maternal perceptions of herself, her baby and the relationship between the two of them. From this perspective, therapeutic change involves elements that are generic and common to different approaches. Specifically, this model of psychotherapy and change can be understood as a change in subjective theories, in other words, a transformation in the ways in which the patient understands himself, his relationship with the world, or a situation and gives a new meaning to a certain experience (Krause, 2011; Krause \& Altimir, 2018). The patient's reality is gradually transformed through the psychotherapeutic process, and its level of elaboration increases. Therapeutic changes may include cognitive, affective, and evaluative processes that are implicitly expressed in the patient's behaviour during the session (in-session) or outside the session (extra-session).

However, this type of research can pose several challenges that make it difficult to access the knowledge and understanding of the mechanisms involved in therapeutic change. Likewise, despite the evidence about the effectiveness of video-feedback and the incipient evidence about its mechanisms of change, research on processes of changes in this area are still scarce, which, therefore, can make it difficult to make decisions about the appropriateness of treatments for certain patients, such as women with peripartum depression symptomatology.

\section{The present study}

Psychotherapeutic process research aims to answer the question 'what changes when you change?' within episodes of change during psychotherapy.

In this study we aim to explore, describe, and illustrate the intervention process and therapeutic change expression, through the generic change indicators (GCI; Krause et al., 2006), using video-feedback, which is an interven- tion strategy that has ample evidence about its effectiveness in outcome studies (Juffer, Bakermand-Kranenburg \& Van Ijzendoorn, 2018).

As an exploratory study, it also aims to test the applicability of this system to a dyadic intervention with videofeedback. Specifically, we observed and analysed a single therapeutic process of a brief mentalization-informed intervention with video-feedback for mothers with depressive symptoms and their babies.

\section{Materials and methods}

A single case qualitative study using GCI in psychotherapy was conducted. In this psychotherapeutic process study, episodes of change (EC; Krause et al., 2006) were the main unit of analysis.

This single case intervention process is part of the sample of a randomized feasibility trial delivered online that aims to improve maternal depressive symptoms, maternal sensitivity and mentalizing by using video-feedback (Trial registration: NCT0474873 in Olhaberry et al., 2021).

Within the randomized feasibility trial, study participants were referred by local public health centres. As inclusion criteria, participants must have scored more than 5 points on the EPDS (Cox et al., 1987), which is commonly applied at 2 and/or 6 months postpartum.

Potential participants are invited and if they agree to participate, the research coordinator contact them and establishes contact with the therapist who will carry out the intervention, considering participant's time availability. First, participants sign the informed consent form, followed by the pre-intervention assessment consisting of completing questionnaires, the first video recording of a mother-infant interaction, and a semi-structured interview.

\section{Intervention}

Participation of mothers within the project lasts about 5 months and considers different components: pre-intervention assessment (week 1), four sessions of video-feedback intervention, and informational material (psychoeducational cards) sent after each session of intervention (week 2, 3, 4 and 5). After two weeks and 3 months, follow-up assessments are conducted.

Each intervention session is conducted following a protocol on video-feedback in early childhood (Olhaberry, León, y Sieverson, 2021) and the video-feedback mentalization-informed protocol from the main research (Olhaberry et al., 2021).

The intervention aims to improve maternal sensitivity and mentalizing by using a model based on the videofeedback methodology in a virtual modality.

This intervention was developed considering previous experiences from the research team using video-feedback 
in a short and home-visit intervention with mother-baby dyads with depressive symptoms and relationship difficulties (Olhaberry, Leon, Seguel, \& Mena, 2015) and with mother-father-child triads (Olhaberry et al., 2019). In turn, this cited intervention is based on previous evidence of attachment-based intervention using video-feedback as their main intervention strategy, namely attachment and biobehavioural catch-up (ABC), Video-feedback Intervention to promote positive parenting (VIPP-SD), video intervention therapy (VIT), and opportunities for the development of sensitive, effective and affective interactions model (ODISEA).

The implementation model considers 30 hours of training for therapists, including a 2-hours weekly reflective supervision group in which videos are analysed and each case is discussed, along with the therapist independent work on the case between sessions.

Each intervention session has the same structure. The videos used to carry out the video-feedback are recorded remotely by the therapist during pre-intervention assessment and sessions 1, 2 and 3 of intervention and each one used in the next session.

Segments of approximately 5 to 40 seconds are selected by the therapist. During the video-feedback, the therapist stops the video when a moment of positive interaction between both participants is identified, as this will be the image on which the reflection will be made. It is recommended to show the complete video unless negative segments are identified (i.e., segments in which the mother appears as hostile or insensitive, when the child appears severely under regulated). Specific goals to be achieved in each selected segment must be identified (i.e., to enhance mentalizing) and comments and questions to be made by the therapist should be defined, and these should be linked to the goal of each selected segment (i.e., How do you imagine that your baby felt when you took her hands, and you sang her song together?).

\section{Researcher's reflexivity}

As mentioned above, the present study is part of a feasibility trial.

In the present case study, seven researchers and two therapists from the above-mentioned research project team analysed the case of Ms. A and her baby S. One of the investigators is both the author of this paper and the therapist who treated Mrs. A. The second author is the principal investigator of the main study, and 6 of the investigators who analyzed the case are coauthors of this article (MO, JM, JD, MJL, SC, and FL). All of them, in addition to 2 therapists who participated in the case analysis ( $\mathrm{SV}$ and $\mathrm{CH}$ ), attended the supervisions in which Ms. A's case was presented. MO is a psychologist and researcher with extensive experience working with mothers in the peripartum period with depressive symptoms and video feedback in dyadic and triadic interventions. JD and JM are psychologists and researchers with experience in qualitative methodologies and psychotherapy process research, as well as the expert judges from this study. CS is psychologist and researcher in the field of peripartum mental health with experience in dyadic and triadic intervention using video-feedback. MJL is a psychologist and researcher in the field of early childhood psychotherapy and coauthor with MO y CS of the video-feedback guide that guided the intervention of this study. SC is a psychologist and FL psychiatrist. Both are experienced researchers in the field of clinical psychology and video-feedback intervention. These researchers are coauthors of the paper and participated in the analysis of the case. Finally, SV was one of the CGI coders.

In addition to the therapeutic work, there was one weekly group supervision for video-feedback therapists based on the reflective supervision model (ShamoonShanok, 2006) conducted by MO, CS and MJL. This is a key component of the intervention where attention is paid to the experience of each of the intervention participants, that is, the experience of the supervisor, the child, the caregiver and the therapist. In this space, the supervisor can contain the intensity of the therapist's experiences in working with the family and based on this experience, contain, modulate and transform the experiences and reactions of the family, giving them meaning; which in turn calms the child, the parents and the therapist (Murphy, Steele \& Steele, 2012).

It is important to clarify that CS, MO, JM, FL, MJL, $\mathrm{SC}$ and $\mathrm{CH}$ are all trained in mentalization-based treatment (CS, MO, FL, MJL, SC and CH for children and JM and families) and all of the authors of this paper with different trajectories of clinical experience.

\section{Procedure}

\section{Data collection}

The pre-intervention assessment and 4 intervention sessions were observed and coded for GCI by 2 trained coders. Coded episodes were validated through intersubjective agreements (Flick, 2009) and confirmed in consensus meetings with expert judges.

The coding process consisted of the observation of the intervention process in audio and video by a pair of trained encoders (directly or from recordings), who independently identified the moments of change and the type of specific indicator based on the Manual of Observation, Recording and Coding of Episodes of Change and Stagnation (Chilean Research Program in Psychotherapy and Change Version 2.0, 2012), and agreed in a later meeting.

The process of identifying the moment of change and the indicator itself is simultaneous and, once the moment of change is established, the content is ratified through the review of the transcript of the session. 


\section{Analysis procedure}

GCI (Krause et al., 2006) (see Table 1): Patient's ongoing change was determined through the identification of EC and MC that occurs within it (Krause et al., 2006). The MCs signal the end of the EC, and each MC was then labelled with one of the 19 GCIs (Krause, 2005; Krause et al., 2006). Each of the 19 GCIs may appear more than once during the intervention and GCIs of different levels independent of the time of the intervention may also appear.

An important criteria for the rating of indicators of change is the novelty criteria. This criteria is applied to the themes that emerge and the level of elaboration made by the patient about that theme. For an indicator of change to be established, the elaboration of a particular theme has to be appearing for the first time.

For example: 'Questioning of habitual understanding, behaviour or emotions' may appear first in relation to the patient's perception of her own childhood memories and later may appear with regards to her perception of her maternal role. Other criteria for its definition are theoretical correspondence with the GCI model, actuality/distinction of intra- and extra-session change, and, finally, the consistency criteria. This criterion refers to coherence between the patient's verbal and non-verbal expressions. Also, there needs to be no contradiction between what is said in one moment and in another.
The 19 indicators can be grouped theoretically into three main stages of change (Altimir et al., 2010) (see Table 1), namely I: 'Initial consolidation of the structure of the therapeutic relationship' (from 1 to 7), II: 'Increase in permeability toward new understandings' (from 8 to 13), and III: 'Construction and consolidation of a new understanding' (from 14 to 19).

\section{The case of Ms. A}

For this article, we chose a participant who completed the intervention and showed high adherence to the treatment (e.g., complied with sessions, was collaborative within the intervention session, and had extra-session components such as questionnaires and process measures).

$\mathrm{Ms} \mathrm{A}$ is a 39-year-old woman, and $\mathrm{S}$. is her 10-monthold baby at the beginning of the intervention. Ms A and $\mathrm{S}$ have started to live together with Mr C (26-year-old), the father of S and partner of Ms A since she was in her eighth month of pregnancy. They come from a low-income background, and both Ms A and her partner work as shift job employees. Ms A works as a supermarket helper, and $\mathrm{Mr}$ $\mathrm{C}$ works as a security guard.

Ms. A agreed to participate in the intervention, expressing as her main concern 'It is a good instance to find out if I am doing well', and she often compares her current motherhood with her as a mother of her older children. Ms. A has three older children (of 18, 15 and 10 years old) from

Table 1. Generic change indicators.

Stage I: Initial consolidation of the structure of the therapeutic relationship

1. Acceptance of the existence of a problem

2. Acceptance of his/her limits and the need for help

3. Acceptance of the therapist as a competent professional

4. Expression of hope

5. Questioning of habitual understanding, behaviour, and emotions

6. Expression of the need for change

7. Recognition of his/her own participation in the problems

Stage II: Increase in permeability toward new understandings

8. Discovery of new aspects of self

9. Manifestation of new behaviour or emotions

10. Appearance of feelings of competence

11. Establishment of new connections

12. Reconceptualization of problems and/or symptoms

13. Transformation of valuations and emotions in relation to self or others

Stage III: Construction and consolidation of a new understanding

14. Creation of subjective constructs of self

15. Founding of the subjective constructs in own biography

16. Autonomous comprehension and use of the context of psychological meaning

17. Acknowledgement of help received

18. Decreased asymmetry between patient and therapist

19 Construction of a biographically grounded subjective theory 
her former partner, with whom she had a relationship for 20 years.

They have been divorced for 2.5 years and, since she moved to live alone, they share custody of only the tenyear-old child, who lives with her half of the time. The other two children live with their father, and Ms A has little contact with them (mainly by phone): 'The older children live with him for a reason... because at the beginning I came here and I had nothing, nothing, nothing, nothing. Nothing. (...) So they obviously... Their dad has a much better economic situation than me, and there are things I cannot give the older ones.'

$\mathrm{S}$ was born of an unplanned pregnancy in Ms A's relationship with $\mathrm{MrC}$, and is the fourth daughter of Ms. A and the first from Mr. C. Ms. A and Mr. C began their relationship while she was still living with her ex-husband, even though they were already divorced. During her third trimester of pregnancy, she moved to live alone. Regarding that period, she refers to having felt for not having a job and felt unsupported. She points out: 'because I stopped working for them, I stopped studying for them (older children and her ex-husband)'. She says that after that feeling, she looked for a job and got her current one. In addition to this, Ms. A refers that the separation from her ex-husband was her decision and that it surprised the whole family. This decision, she says, was not respected by her family, and who stopped supporting her and getting in touch with her.

During the course of the intervention, Ms. A begins legal proceedings for custody of her 10-year-old son and, at the end of the intervention, asked her therapist for referrals to begin a psychological process with him.

It should be noted that the intervention process with Ms. A occurs in the context of the COVID-19 pandemic. Thus, it is relevant to consider that besides the changes of the pregnancy and early motherhood period, parenting during the pandemic has been an additional source of stress for parenthood, which has generated instability in women during the peripartum period (Basu et al., 2021; Olhaberry et al., 2021).

\section{Results}

Below, the intervention process is described through the GCI in the case of Ms. A.

\section{Pre-intervention assessment}

In the first meeting from the therapist with Ms. A, the reasons for her consultation were explored. In this context, Ms. A narrated her previous family experience with her exhusband and children. She said that this is a story of separation and that it 'still hurts me'.

It might be noticed that pre-intervention sessions can be experienced as a therapeutic moment for the mother and her baby (Durosini \& Aschieri, 2021). During this pre-assessment intervention, Ms. A shows the first in-session ther- apeutic change associated with her maternity history before the maternity with $\mathrm{S}$.

A GCI from stage I was observed, which manifests itself in the (7) Recognition of one's participation in problems. Regarding the pain she expresses for the separation of her children, the impossibility of taking them to live with her and how she perceives this experience currently influences her experience as a mother of S. The therapist comments to Ms. A, 'I imagine so. Mmhh. In that sense, with $S$ it has been quite different...' and Ms. A states that 'I do not know, I failed at something, but maybe giving them too much maybe is also a part, like, going to the other extreme, is like a negative part. And that is what it costs me with $S$; it costs me a lot. And that's what the father of the S tells me, he tells me that he sees that I give him, that is, when the $S$ cries I go very soon to satisfy as what she wants', 'And maybe that's what I have to stop, but that costs me a lot."

\section{Session 1}

In this session, the first video feedback was made from the video recorded in the pre-intervention session. The video consisted of a free mother-baby interaction of 10 minutes. In addition, a new mother-baby interaction was also recorded in this session. Ms. A was invited to find a comfortable place to be with $\mathrm{S}$ with reachable toys. While together, she was asked to observe $\mathrm{S}$ and participate when $S$ gave him signs that she wanted her mother to be included or needed her.

During this session, a GCI from stage I was identified at the post-video interview (i.e., after the new video recording), expressed in (5) questioning habitual understanding, behaviour, and emotions. Ms. A said that, as she reflected on what had just occurred in the interaction with her daughter, she realized that the way she usually interacts with her daughter was related to the high levels of demands she has on her daughter.

During the post-video interview, the therapist asks, 'now regarding the both of you, what happened now in this moment, has ... happened before?'. Ms. A says that this kind of interaction with her daughter is unusual. She says that she usually sits with $\mathrm{S}$, but she never only observes her, adding that 'Then it was like, yes, it was like nice because, when one does not sit only to observe her, ehh... Sure, I played with her, but I didn't give her time, for example, to know what she really knew. So I had no idea she knew or wanted to put the legos together. I always put them together and pass them on. She disarms them.'

\section{Session 2}

In this session, the second feedback video was made from the video recorded in the previous session. In addition, a new mother-baby interaction was recorded; a singing-and-playing interaction. During video-feedback, the therapist showed a segment of the video where Ms. A 
helps S to stand and walk and then Ms. A takes out some toys to leave the way without obstacles for S.

The analysis carried out by Ms. A, together with the therapist, focuses on the differences between S's autonomy versus independence. Within this analysis, the main concerns of Ms. A were addressed. Specifically, she is worried about the S's high levels of demand on her, and she feels uncomfortable facing the permanent obligation to solve her daughter's difficulties.

Ms. A states that 'It would be different if she were already two years old and... and she were already able to take out her... her obstacles in her way... but, obviously, now I am the one that has to be there... it's me who was there with her, so I had to... emm... help her, help her to take out those toys that were in her way'. The therapist asks Ms. A 'This piece of video that we are watching, what makes you think?'. In Ms. A's response, a GCI from stage II was observed: (10) Appearance of feelings of competence.

Ms. A referred again that she feels high demands from her daughter. She also said that although she needs to be told that she is doing it well, somehow she intuitively knows that she is doing the right things: 'Although anyone would tell me 'Hey, but if you have three children, how can you not know', anyone would tell me like this. But it is really forgotten, and it has really been so many years, that, perhaps, I have, of course, before I only dedicated myself to them, at no time me ... it's like, I finished growing one, and it came to another, I raised that one, then it finished and then I raised the other. On the other hand, with S I have spent a long time and... everything was like it was starting over, from scratch. Then... suddenly I feel like I need, ehh, someone to also tell me that what I'm doing is okay, although I know it too, I know in my inside, I sense it's okay too.

\section{Session 3}

In this session, the third video-feedback was held from the previously recorded video. In the previous session, Ms. A was invited to be face to face with $\mathrm{S}$, watching each other's faces, singing a song and then playing.

Again a GCI was observed during the video-feedback. The therapeutic change can be identified at the moment when Ms. A reflects on S's smiling expression. Ms. A says she did not remember it that way and that she feels happy to see it differently now (watching the recording): 'I am glad to see her happy. I think those are things; you know that I don't know, I think I worry too much, I've realized that I worry too much about the mood of my daughter.'.

A GCI from stage II was observed: (11) Establishment of new connections. She describes that what worries her is to see $\mathrm{S}$ more often upset than happy. She believes that what concerns herself is that she does not want her daughter to have a bad time: 'Maybe I see it that way, and it is not so, because, maybe children, obviously, she, emm demands so much for my attention, that I feel sorry for not being able, emm to satisfy her needs. First, I cannot be on her all day. Second, because maybe it's not right either... that I am with her all day, all, all, all, all day, ehh, with her, that is, she also must learn, but I am distressed that she feels unhappy. That is what happens to me. And no, I do not know why it happens to me with her ... maybe it is because I lived such a difficult time... I imagine that maybe that is why I don't want her to feel unhappy and so, maybe...'

\section{Session 4}

In the previous session's recording, Ms. A was invited to share a feeding time with $\mathrm{S}$. The changes observed in this session happen again within the video-feedback process, and two GCI were observed in this last session of intervention.

The first GCI was observed when Ms. A discovers a behaviour that she did not remember from the video recording. In the videoed interaction $\mathrm{S}$ makes a gesture that she then imitates. The gesture that $\mathrm{S}$ makes is related to the food and the feeling of satiety. When the mother tells her, 'you do not want more', S responds with a gesture that may indicate 'I want just a little' more, and the mother imitates this gesture accompanying it with verbalization. This gesture goes unnoticed by Ms. A, and when she saw the video, she realized this interaction with her baby, referring to feeling surprised by how $\mathrm{S}$ understands everything adults express and respond in her way. The therapist asks Ms. A, 'How else does it make you feel? Or what else makes you think?'. At that moment, a GCI from stage II was observed: (11) Establishment of new connections. Ms. A describes new associations between her mental states and what happens to her daughter. 'She understands what I tell her; she understands what I am asking of her; she understands what we are doing. So, obviously, that gives me joy because, ehh, I see that, to her, ehh, although I do not realize it, she is learning things day by day, things that I do not even realize', 'Yes. I think you live life so fast and you're always in such a hurry and you're always doing everything... I think watching videos like this, so carefully, ehh, there really are a lot of things going on around you that you don't realize.'

In a second part of this intervention session, a segment was watched in which Ms. A offers one more tablespoon of food to $\mathrm{S}, \mathrm{S}$ responds that she does not want more moving her head and Ms. A responds not giving $\mathrm{S}$ more food.

After watching this segment, the therapist asked Ms. A why she did not insist on giving S more food. In her response, a GCI from stage was observed in Ms. A: (15) Founding of the subjective constructs in own biography. Ms. A manifested awareness that some of her behaviors and attitudes might relate to her own childhood experiences. In this way, she links her childhood experiences with her later development into adulthood and motherhood with $\mathrm{S}$ and her development.

'Yes, sure, that it for me like that... forcing them makes 
everything, their personality, delays, children start to inhibit themselves. Me too, I say this based on my own experience, maybe, too. I was very shy...', 'Yes, because when I was a child I was very shy, and well, maybe when I was a child nobody listened to my opinion... for many years, I let others think for myself', 'With my mother, with all the people I think. Until I was an adult, then I realized or well, that is what I am thinking now, because at that precise moment one does not realize that well, all these things come from when one is very young'

\section{Generic change indicators in the intervention process}

Ms. A manifested changes from the moment of the initial evaluation, increasing the hierarchical level of the GCI throughout the intervention (see Table 2).

GCI are presented associated with the situation of video recording and mainly when observing herself during video-feedback. In session 1 of the intervention, a GCI was observed related to the post-video recording interview and to the proposed invitation made to Ms. A to interact with her baby. In sessions 2, 3 and 4 GCI were observed that arises in the context of video-feedback and the observation and analysis of the interactions between her and $\mathrm{S}$.

Besides, the level of the GCI increased session-by-session process, starting with GCI from stage I (i.e., changes related to the 'Initial consolidation of the structure of the therapeutic relationship'), both in the pre-intervention and first session. Then, in sessions 2 and 3, GCI from stage II (i.e., related to 'increase in permeability toward new understandings'). It is important to consider that in session 4, a GCI from stage II was observed and, towards the end of the session, a GCI from stage III was observed related to the "Construction and consolidation of a new understanding'.

\section{Discussion}

The main goal of this study was to explore and describe the intervention process and therapeutic change expression through the GCI (Krause et al., 2006) answering the question of 'what changes when you change?' within meaningful episodes in a brief mentalization-informed in- tervention with video-feedback with a mother with depressive symptoms and her baby (Ms. A and S).

Regarding the key question of the study (i.e., 'what changes when you change') and based on the GCI model, it has been proposed that what changes within the psychotherapeutic process are the subjective theories and internal narratives of each patient. These changes can also progress through the process of intervention (Krause, 2011; Krause \& Altimir, 2018).

In the case of Ms. A with S, we hypothesize that the fact of observing videos of herself interacting with her daughter and doing this in the company of the therapist made Ms. A feel seen and validated in her motherhood. This, in turn, made her perceive herself and her daughter from a more reflective perspective, understanding that $\mathrm{S}$ has a mind of her own (e.g.: when she says that she did not realize that $\mathrm{S}$ wanted to put the legos together until she observed her) (Beebe, 2003; Steele et al., 2014).

According to Ms. A's therapeutic progress it is possible to see how she develops her observational skills concerning herself and her baby during the intervention, which also allows her to set herself as a mother of S with a greater sense of coherence and well-being. The fact that the mother felt validated in her observations by the therapist allowed Ms. A to observe her daughter's needs with greater sensitivity and less guilt. That is, observing oneself in the presence and accompanied by the therapist as a secure base, allows exploring both the outer and inner world from a regulated emotional stance and facilitates the discovery of new aspects in the child, enhancing a more sensitive attitude with less self-criticism in the adult.

An essential element of early parenting interventions is the therapist accompaniment exploring the parent's own top-down and bottom-up histories of parenting. In this case, Ms. A was able to explore episodes of her parenting history and childhood experiences and connect these events with her own motherhood with S. For example, when she explained her conscious choice of listening to her daughter's 'no' as something linked to her memories of not having been seen and heard enough as a child.

We hypothesise that the progress of the GCI sessionby-session and the fact that they were observed mainly during video-feedback might be related with two key el-

Table 2. Generic change indicators session-by-session and the moment of occurrence.

\begin{tabular}{llll}
\hline Session & Indicator & Stage & Session moment \\
\hline Pre-intervention assessment & 7 & I & Reason for consultation and main concerns \\
\hline Session 1 & 5 & I & Post-video interview \\
\hline Session 2 & 10 & II & Video-feedback \\
\hline Session 3 & 11 & II & Video-feedback \\
\hline Session 4 & 11 & II & Video-feedback \\
\hline Session 4 & 15 & III & Video-feedback \\
\hline
\end{tabular}


ements, namely, Ms. A's abilities and intervention's characteristics, in particular, the use of video-feedback.

First, the relatively high GCI observed in the pre-intervention assessment, might be related to aspects that precedes the intervention process with Ms. A as well as related with her main concerns and reason for consultation. It is so that, in the pre-intervention assessment Ms. A says that she has been thinking about her daughter's development, motivated by what she sees and talks with other mothers in the health centre. She reflects on how normal S's behaviors are and also how appropriate are her concerns as a mother: 'I see that the other children are quiet, silent, but she is not, and so I think this is a good opportunity to change... or ... well, there are doubts; I have questions about parenting, even though I have other three children, I have forgotten many things'.

Second, GCIs were able to be observed in a brief time of intervention. Generally, studies about GCI report advanced levels of them within longer therapies (Krause et al., 2006). On this regard the appearance of GCI in the case of Ms. A can be explained not only by her reflective abilities but also by components of the intervention itself.

The use of video-feedback enabled Ms. A to explore and connect -accompanied by the therapist- with her childhood rearing experiences and her motherhood feelings and without overwhelm. This scenario allowed her to explore her motherhood from a secure base, being able to set off her reflective capacities (Beebe, 2010; Malberg, 2015; Murphy et al., 2012).

Consistent with previous GCI studies' findings, the progress of the therapeutic changes in Ms. A increased gradually, session-by-session, reaching its higher level at the end of the last session of the video feedback intervention (Krause et al., 2006; Krause \& Altimir, 2018).

In Ms. A case, no extra-session GCI were identified. Although some elements appeared that showed that she was making autonomous reflections that were echoed in the changes on her daily routine (e.g., 'we decide that when we are both free, we give each other an hour a day, for example, an hour for me and an hour for him, during the day (...) and it really works a lot, because I think is necessary to have some me-time. A moment for resting or for doing something for me'). Also, the fact that she brought to her daily life the processes of observation and curiosity about S's inner world (e.g., After the sessions, I remain like thinking, thinking in what we have talked and it is like this remains in me... then Slooks at me and I tell her 'what is S thinking?').

It is hypothesized that in longer interventions these expressions of more incipient therapeutic change could become GCI, like in the above mentioned studies.

\section{Conclusions}

Our results suggest that GCI's model is feasible to be used to analyse and comprehend interventions in early childhood. The model provides an understanding of the intervention from the therapeutic change, which might support psychotherapist training and supervision, thus contributing to clinical and research. Additionally, this study contributes to the growing body of knowledge regarding processes of change within video-feedback based interventions.

One key result of this study is that GCI model is useful to identify and analyse $\mathrm{EC}$ and $\mathrm{MC}$ in the parent during dyadic interventions. Thus, the proposed methods have been able to be implemented in a short, dyadic intervention that uses video-feedback.

This study is both a pioneer and incipient research within the psychotherapy process research paradigm, which may contribute to the growing body of evidence supporting the training and supervision of psychotherapists.

In this regard, our study contributes to the design of interventions beyond the outcome perspective. Our findings suggest that interventions could be designed considering a series of shift points (EC and $\mathrm{MC}$ ), in addition of main outcomes.

The presented case of Ms. A shows a significant change in her depressive symptomatology comparing before and after the intervention, lowering from clinical to non-clinical levels. Even though the therapeutic changes expressed by Ms. A throughout the intervention are not directly related with the decrease in the depressive symptomatology, these changes are important (for Ms A, her daughter and the researchers).

The therapeutic changes observed in the case of Ms. A reflect the transformations in the narrative and understanding that she had about herself; in general and as S's mother. In this sense, the GCI's could be linked with an intervention informed by mentalizing because the changes presented by Ms. A imply: the identification of mental states in herself as S's mother; the recognition of the existence of multiple perspectives, and the mutual influence between those perspectives and her parenting.

The use of video-feedback may become a strategy of intervention that provides an environment where the therapist is for the mother both secure base and save heaven (Steele \& Steele, 2017). In this regard, it is also possible to link the therapeutic change in Ms. A to the experience of safe haven for exploration provided by the therapist, which allows the patient to explore her experience and also can contribute to decrease levels of depressive symptomatology.

Within the limitations of the study, since it is a single case study, the results presented are preliminary. In any case, they open a new field of research that is pioneer in relation to the mechanisms that underlie therapeutic change.

On the other hand, GCIs only allow to describe the subjective change of the mother but they do not necessarily address therapeutic changes at a relational level between the mother and her baby. In this regard, a question 
remains open in relation to the ongoing therapeutic change in terms of the dyad, which would not be answered only through the pre- and post-intervention results.

\section{References}

Anderson, T., McClintock, A. S., Himawan, L., Song, X., \& Patterson, C. L. (2016). A prospective study of therapist facilitative interpersonal skills as a predictor of treatment outcome. Journal of Consulting and Clinical Psychology, 84(1), 57-66. doi:10.1037/ccp0000060.

Antonsen, B. T., Johansen, M. S., Rø, F. G., Kvarstein, E. H., \& Wilberg, T. (2016). Is reflective functioning associated with clinical symptoms and long-term course in patients with personality disorders? Comprehensive Psychiatry, 64, 46-58. doi:10.1016/j.comppsych.2015.05.016.

Basu, A., Kim, H. H., Basaldua, R., Choi, K. W., Charron, L., Kelsall, N., \& Koenen, K. C. (2021). A cross-national study of factors associated with women's perinatal mental health and wellbeing during the COVID-19 pandemic. PLoS One, 16(4), e0249780. doi:10.1371/journal.pone.0249780.

Beebe, B. (2003). Brief mother-infant treatment: Psychoanalytically informed video feedback. Infant Mental Health Journal: Official Publication of the World Association for Infant Mental Health, 24(1), 24-52. doi:10.1002/imhj.10042.

Beebe, B. (2010). Mother-Infant Research Informs Mother-Infant Treatment. Clinical Social Work Journal, 38(1), 17-36. doi:10.1007/s10615-009-0256-7.

Behrendt, H. F., Scharke, W., Herpertz-Dahlmann, B., Konrad, K., \& Firk, C. (2019). Like mother, like child? Maternal determinants of children's early social-emotional development. Infant Mental Health Journal, 40(2), 234-247. doi: 10.1002/imhj.21765.

Bernstein, D. P., Stein, J. A., Newcomb, M. D., Walker, E., Pogge, D., Ahluvalia, T., Stokes, J., Handelsman, L., Medrano, M., Desmond, D., \& Zule, W. (2003). Development and validation of a brief screening version of the Childhood Trauma Questionnaire. Child Abuse \& Neglect, 27(2), 169-190. doi:10.1016/s0145-2134(02)00541-0.

Capella, C., Gutiérrez, C., Rodríguez, L., \& Gómez, C. (2018). Change during psychotherapy: the perspective of children and adolescents who have been sexually abused. Research in Psychotherapy: Psychopathology, Process, and Outcome, 21(1). doi:10.4081/ripppo.2018.288.

Carter, S. L., Osofsky, J. D., \& Hann, D. M. (1991). Speaking for the Baby: A therapeutic intervention with adolescent mothers and their infants. Infant Mental Health Journal, 12(4), 291301. doi:10.1002/1097-0355(199124)12:4<291::AIDIMHJ2280120403>3.0.CO;2-3.

Castañón, C. \& Pinto, J. (2008). Mejorando la pesquisa de depresión posparto a través de un instrumento de tamizaje, la escala de depresión posparto de Edimburgo. Revista Médica de Chile, 136(7), 851-858. doi:10.4067/S003498872008000700005.

Cox, E. Q., Sowa, N. A., Meltzer-Brody, S. E., \& Gaynes, B. N. (2016). The perinatal depression treatment cascade: baby steps toward improving outcomes. The Journal of Clinical Psychiatry, 77(9), 1189-1200. doi:10.4088/JCP.15r10174.

Doria, M. V., Kennedy, H., Strathie, C., \& Strathie, S. (2013). Explanations for the success of video interaction guidance (VIG). The Family Journal, 22(1), 78-87. doi:10.1177/ 1066480713505072 .
Duarte, J., Martinez, C., \& Tomicic, A. (2020). Episodes of meeting in psychotherapy: an empirical exploration of patients' experiences of subjective change durin their psychotherapy process. Research in Psychotherapy: Psychopathology, Process, and Outcome, 23(1). doi:10.4081/ripppo.2020.440.

Durosini, I., \& Aschieri, F. (2021). Therapeutic assessment efficacy: A meta-analysis. Psychological Assessment. [Epub ahead of print].

Ekeblad, A., Falkenström, F., \& Holmqvist, R. (2016). Reflective functioning as predictor of working alliance and outcome in the treatment of depression. Journal of Consulting and Clinical Psychology, 84(1), 67-78. doi:10.1037/ccp0000055.

Feldman, R. (2015). The adaptive human parental brain: implications for children's social development. Trends in Neurosciences, 38(6), 387-399. doi:10.1016/j.tins.2015.04.004.

Fischer-Kern, M., Doering, S., Taubner, S., Hörz, S., Zimmermann, J., Rentrop, M., Schuster, P., Buchheim, P., \& Buchheim, A. (2015). Transference-focused psychotherapy for borderline personality disorder: change in reflective function. The British Journal of Psychiatry: the journal of mental science, 207(2), 173-174. doi:10.1192/bjp.bp.113.143842.

Flick, U. (2009). An introduction to qualitative research (4th ed.). London: Sage.

Gullestad, F. S., Johansen, M. S., Høglend, P., Karterud, S., \& Wilberg, T. (2013). Mentalization as a moderator of treatment effects: findings from a randomized clinical trial for personality disorders. Psychotherapy research: journal of the Society for Psychotherapy Research, 23(6), 674-689. doi:10.1080/ 10503307.2012.684103.

Hahn-Holbrook, J., Cornwell-Hinrichs, T., \& Anaya, I. (2018). Economic and Health Predictors of National Postpartum Depression Prevalence: A Systematic Review, Meta-analysis, and Meta-Regression of 291 Studies from 56 Countries. Frontiers in Psychiatry, 8, 248. doi:10.3389/fpsyt.2017.00248.

Juffer, F., \& Steele, M. (2014). What words cannot say: The telling story of video in attachment-based interventions. Attachment \& Human Development, 16(4), 307-314. doi:10.1080/ 14616734.2014.912484.

Juffer, F., Bakermans-Kranenburg, M. J., \& Van Ijzendoorn, M. H. (2017). Video-feedback intervention to promote positive parenting and sensitive discipline: Development and metaanalytic evidence for its effectiveness. In H. Steele \& M. Steele (Eds.), Handbook of attachment-based interventions (pp. 1-26). The Guilford Press.

Kennedy, H., Landor, M., \& Todd, L. (2011). Video Interaction Guidance. A relationship-based intervention to promote attunement, empathy, and wellbeing. Jessica Kingsley Publishers: London.

Krause, M. (2011) Psicoterapia y Cambio: Una mirada desde la subjetividad. Santiago: Ediciones Universidad Católica de Chile; (2da edición).

Krause, M., Altimir, C., Pérez, J. C., Echávarri, O., Valdés, N., \& Strasser, K. (2016). Therapeutic verbal communication in change episodes: a comparative microanalysis of linguistic basic forms/Comunicación verbal terapéutica en episodios de cambio: un microanálisis comparativo de las formas lingüísticas básicas. Estudios de Psicología, 37(2-3), 514-547. doi:10.1080/02109395.2016.1227.

Krause, M., \& Altimir, C. (2018). El Programa Chileno de Investigación del Cambio en Psicoterapia. Revista Brasileira de Psicoterapia, 20(3), 149-173.

Krause, M., Parra, de la Parra, G., Arístegui, R., Dagnino, P., Tomicic, A., Valdés, N., Vilches, O., Echávarri, O., Ben-Dov, P., Reyes, L., Altimir, C., \& Ramírez, I. (2006). Indicadores genéricos de cambio en el proceso psicoterapéutico. Revista 
Latinoamericana de Psicología, 38(2), 299-325.

Lefkovics, E., Rigó, J., Jr, Kovács, I., Talabér, J., Szita, B., Kecskeméti, A., Szabó, L., Somogyvári, Z., \& Baji, I. (2018). Effect of maternal depression and anxiety on mother's perception of child and the protective role of social support. Journal of Reproductive and Infant Psychology, 36(4), 434-448. https://doi.org/10.1080/02646838.2018.1475726.

Letourneau, N. L., Dennis, C. L., Cosic, N., \& Linder, J. (2017). The effect of perinatal depression treatment for mothers on parenting and child development: A systematic review. Depression and Anxiety, 34(10), 928-966. doi:10.1002/da.22687.

McFarquhar, T., Luyten, P., \& Fonagy, P. (2018). Changes in interpersonal problems in the psychotherapeutic treatment of depression as measured by the Inventory of Interpersonal Problems: A systematic review and meta-analysis. Journal of Affective Disorders, 226, 108-123. doi:10.1016/j.jad. 2017.09.036.

Midgley, N., Anderson, J., Grainger, E., Nesic-Vuckovic, T., \& Urwin, C. (Eds.). (2009). Child psychotherapy and research: New approaches, emerging findings. Routledge/Taylor \& Francis Group. doi:10.4324/9780203872154.

Monk, C., Spicer, J., \& Champagne, F. A. (2012). Linking prenatal maternal adversity to developmental outcomes in infants: the role of epigenetic pathways. Development and Psychopathology, 24(4), 1361-1376. doi:10.1017/S0954579412000764.

Morgan, J. E., Channon, S., Penny, H., \& Waters, C. S. (2021). Longitudinal studies examining the impact of prenatal and subsequent episodes of maternal depression on offspring antisocial behaviour. European Child \& Adolescent Psychiatry, 30(1), 5-40. doi:10.1007/s00787-019-01447-w.

Morrison, J. (2015). DSM-5® Guía para el diagnóstico clínico. Editorial El Manual Moderno.

Murphy, A., Steele, M. \& Steele, H. (2012). From out of sight, out of mind to in sight and in mind: enhancing reflective capacities in a group attachment-based intervention. In: J. E. Bettmann \& D. D. Friedman (Eds.), Attachment-based Clinical Work with Children and Adolescents (237-255). New York, NY: Springer Science \& Business Media.

Newton, K., Taylor Buck, E., Weich, S., \& Uttley, L. (2020). A review and analysis of the components of potentially effective perinatal mental health interventions for infant development and mother-infant relationship outcomes. Development and Psychopathology, 1-18. doi:10.1017/S0954579420001340.

Olhaberry, M., Escobar, M., San Cristóbal, P., Santelices, M., Farkas, Ch., Rojas, G., \& Martínez, V. (2013). Psychological perinatal interventions in maternal depression and motherchild bond: A systematic review. Terapia Psicológica, 31(2), 249-261. doi:10.4067/S0718-48082013000200011.

Olhaberry, M., León, M. J., Seguel, M., \& Mena, C. (2015). Video-feedback intervention in mother-baby dyads with depressive symptomatology and relationship difficulties. Research in Psychotherapy: Psychopathology, Process and Outcome, 18(2).

Olhaberry, M., León, M. J., Sieverson, C., Escobar, M., Iribarren, D., Morales-Reyes, I., \& Leyton, F. (2019). Is it possible to improve early childhood development with a video-feedback intervention directed at the mother-father-child triad? Research in Psychotherapy: Psychopathology, Process, and Outcome, 22(2).

Olhaberry, M., León, M. \& Sieverson, C. (2021). Guía para la intervención psicoterapéutica con Video-Feedback: 0 a 5 años: para la promoción del desarrollo socio-emocional infantil, la calidad de las relaciones familiares, mentalización y sensibilidad parental. Off-line guide.

Olhaberry, M., Leyton, F., Moran, J., León, M. J., Sieverson, C.,
Muzard, A., \& Costa-Cordella, S. (2021). Internet Mentalization Informed Video Feedback (MI-VF) Intervention to Improve Parental Sensitivity in Mother-Infant Dyads with Maternal Depressive Symptoms: Study Protocol for a Randomized Controlled Feasibility Trial. Pre-print. doi:10.21203/rs.3.rs-458921/v1.

Olhaberry, M., Sieverson, C., Franco, P., Romero, M., Tagle, T., Iribarren, D., Honorato, C. y Muzard, A. (2021). [Confinamiento por COVID-19: Salud mental en el embarazo y la parentalidad temprana]. Infant Mental Health Journal [In press].

Orlinsky D. E., \& Howard K. I. (1987). A generic model of psychotherapy. J. Integr. Eclectic Psychotherapy, 6, 6-27.

Racine, N., Zumwalt, K., McDonald, S., Tough, S., \& Madigan, S. (2020). Perinatal depression: The role of maternal adverse childhood experiences and social support. Journal of Affective Disorders, 263, 576-581. doi:10.1016/j.jad.2019.11.030.

Reading, R. A., Safran, J. D., Origlieri, A., \& Muran, J. C. (2019). Investigating therapist reflective functioning, therapeutic process, and outcome. Psychoanalytic Psychology, 36(2), 115-121. doi: 10.1037/pap0000213.

Rollè, L., Prino, L. E., Sechi, C., Vismara, L., Neri, E., Polizzi, C., Trovato, A., Volpi, B., Molgora, S., Fenaroli, V., Ierardi, E., Ferro, V., Lucarelli, L., Agostini, F., Tambelli, R., Saita, E., Riva Crugnola, C., \& Brustia, P. (2017). Parenting stress, mental health, dyadic adjustment: a structural equation model. Frontiers in Psychology, 8, 839. doi:10.3389/fpsyg.2017. 00839.

Shamoon-Shanok, R. (2006). Reflective supervision for an integrated model: What, why, and how? In G. M. Foley \& J. D. Hochman (Eds.), Mental health in early intervention: Achieving unity of principles and practice (pp 343-379). San Francisco: Jossey-Bass.

Steele, M., Steele, H., Bate, J., Knafo, H., Kinsey, M., Bonuck, K., Murphy, A. (2014). Looking from the outside in the use of video in attachment-based interventions. Attachment \& Human Development, 16(4), 402-415. doi:10.1080/ 14616734.2014. 912491.

Steele, H., \& Steele, M. (Eds.). (2017). Handbook of attachmentbased interventions. New York, NY: Guilford Publications.

Stein, A., Pearson, R. M., Goodman, S. H., Rapa, E., Rahman, A., McCallum, M., \& Pariante, C. M. (2014). Effects of perinatal mental disorders on the fetus and child. The Lancet, 384(9956), 1800-1819. doi:10.1016/S0140-6736(14)61277-0.

Taubner, S., Kessler, H., Buchheim, A., Kächele, H., \& Staun, L. (2011). The role of mentalization in the psychoanalytic treatment of chronic depression. Psychiatry: Interpersonal and Biological Processes, 74(1), 49-57. doi:10.1521/psyc.2011.74. 1.49 .

Tronick, E. (2007). The neurobehavioral and social-emotional development of infants and children. New York, NY: Norton.

Tronick, E., \& Reck, C. (2009). Infants of depressed mothers. Harvard review of Psychiatry, 17(2), 147-156. doi:10.1080/10673220902899714.

Vismara, L., Rollè, L., Agostini, F., Sechi, C., Fenaroli, V., Molgora, S., Neri, E., Prino, L. E., Odorisio, F., Trovato, A., Polizzi, C., Brustia, P., Lucarelli, L., Monti, F., Saita, E., \& Tambelli, R. (2016). Perinatal parenting stress, anxiety, and depression outcomes in first-time mothers and fathers: A 3to 6-months postpartum follow-up study. Frontiers in Psychology, 7, Article 938. doi:10.3389/fpsyg.2016.00938.

Wallin, D. J. (2012). El apego en psicoterapia. Desclée de Brouwer. 